Bryn Mawr College

Scholarship, Research, and Creative Work at Bryn Mawr College

2008

\title{
Investigating Effects of Invasive Species on Plant Community Structure
}

Wilfred A. Franklin

Bryn Mawr College, wfrankli@brynmawr.edu

Let us know how access to this document benefits you.

Follow this and additional works at: http://repository.brynmawr.edu/bio_pubs

Part of the Biology Commons

\section{Custom Citation}

Franklin, W. "Investigating Effects of Invasive Species on Plant Community Structure."American Biology Teacher 70, no. 8 (2008): 479-482.

This paper is posted at Scholarship, Research, and Creative Work at Bryn Mawr College. http://repository.brynmawr.edu/bio_pubs/4

For more information, please contact repository@brynmawr.edu. 
Investigating Effects of Invasive Species on Plant Community Structure

Wilfred Franklin

The American Biology Teacher; Oct 2008; 70, 8; Research Library pg. 479

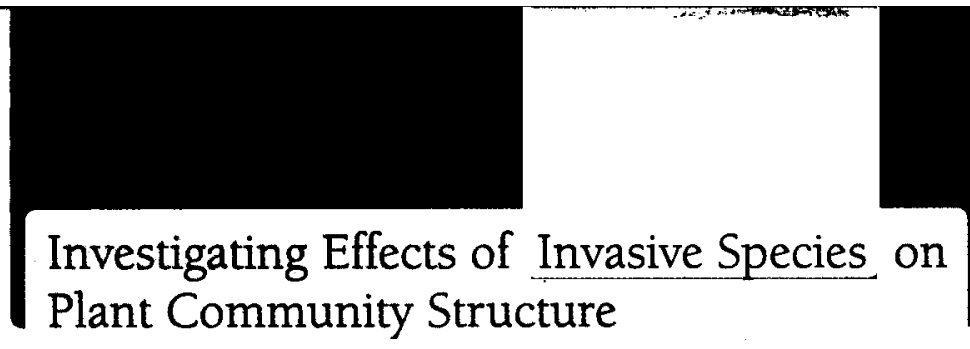

WILFRED FrankLIN

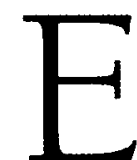

ver wondered what was meant by the old adage "Can't see the forest for the trees"? For my students beginning their study of ecology, the expression takes a new turn: "Can't see the trees for the forest." They explain that when they step into a forest they see a "big green blur" interrupted by brown tree trunks. Bringing the "green blur" (or what Wandersee and Schussler [1999] call "plant blindness") into focus is one of the driving forces behind the following set of activities. Is the blur one species of plant or many? What if anything, is influencing the number and distribution of the plants? How does one distinguish between randomness and organization in plant communities?

Those questions become the basis for a series of laboratory periods devoted to a field study exploring factors influencing forest community structure. Students have the chance to learn local plant species, investigate issues of invasive species, use the line-intercept method of plant sampling, gain experience in experimental design, practice summarizing data with descriptive statistics and, depending on their level, learn more elaborate statistical tests.

When I began planning a field project to introduce undergraduate biology students to ecological concepts, processes, and methodology, I wanted a real problem that would engage them. Fortunately, wild lands and suburban landscapes all over the United States are ripe with just such a problem. Escaped horticultural plants and introduced European and Asian species like English Ivy or Kudzu vine have come to dominate many unmanaged habitats. Invasive species, as they are known, are defined variously in the literature as non-native or introduced species that become established outside of their home range and typically displace or reduce populations of native species (c.f. Campbell \& Reece, 2005). The United States Department of Agriculture (USDA, 2008) defines them as:

a species that is 1) non-native (or alien) to the ecosystem under consideration and 2) whose introduction causes or is likely to cause economic or environmental harm or harm to human health.

Worldwide, an estimated $80 \%$ of endangered species could suffer losses due to competition with or predation by invasive species (Pimentel et al., 2005). This begs the question, what impact will invasive species have on ecosystem services. Healthy ecosystems supply valuable services to humans such as cleaning our water supply, stabilizing topsoil, and supplying agricultural and timber products to our economy. (Vitousek, 1990; Zavaleta \& Hulvey, 2006). The disruption of these crucial services could result in large economic losses. In

WILFRED FRANKLIN is Lecturer and Laboratory Instructor, Biology Department, Bryn Mawr College, Bryn Mawr, PA 19010; e-mail: wfrankli@brynmawr.edu. fact, the estimated damage and control cost of invasive species in the U.S. alone amount to more than $\$ 138$ billion annually (Pimentel et al., 2005). It is in this context that students begin the first of three labs.

\section{Lab 1: Preliminary Field Trip to the Study Site}

The first three-hour laboratory session begins with a short walk to the study site. It is a small (approximately one acre) forested area located on the campus of Bryn Mawr College in southeastern Pennsylvania. The unmanaged woodland is surrounded by residential gardens and, as a consequence, has become a sanctuary for escaped horticultural plants as well as accidentally-introduced plants; the most pervasive of which are Pachysandra and English Ivy. After an initial trip to the study site to learn the dominant plants and qualitatively. describe the area, we discuss - first in small student teams and then as a class - all the possible factors influencing plant community structure at this site.

Moisture and light gradients are the abiotic factors that the students postulate most affect the forest structure. Biotic factors that might influence the forest plant community are a bit more elusive for most students. However, if I ask specifically about plant-animal interactions that might be affecting structure, many will respond that deer-grazing could be a factor. This leads to a discussion of plant-plant interactions, which are often difficult for students to comprehend as they tend to see plants as passive, non-active agents in the environment. Eventually, the light bulb goes on - the English lvy and Pachysandra may be influencing the plant community. The extent of the invasion makes the obscure plant-plant interaction that much more tangible.

At this point I demonstrate the line-intercept method and highlight the descriptive parameters - cover, density, and frequency - that it can measure (see Figure 1 for a flowchart of this method or Cummings \& Smith, 2000 for more in-depth coverage). Upon returning to the classroom from the study site, I display fictitious data and ask all students to calculate percent cover, density, and frequency (Table 1). To help the students struggling with the calculations, I turn to peer-peer instruction, in which student pairs try to convince each other of the correct answers. Once they have mastered these calculations, the stage is set to begin designing a study on the effects of invasive species on plant community structure. Student teams are created and asked to develop a clear study question, hypothesis, prediction, and Data Sheet (see Table 1 for example of Raw Data Sheet). Any biotic or abiotic factors could be investigated but I ask students to focus on invasive species. This allows all the data to be compiled and facilitates statistical analysis. The experimental design converges on a study that compares transects with English Ivy or Pachysandra to those 
Figure 1. Protocol for line-intercept sampling.

1. Stretch the measuring tape on the ground to establish a transect line. Lay it straight and as flat as possible.

2. Go to the first one-meter interval that you randomly generated.

a. On a $50 \mathrm{~m}$ transect line, you will need 10 different starting points. If your random numbers are $2,11,15,20 \ldots$ then go to 2 meters on the transect line and collect data between 2-3 meters. Next, collect data between 11-12 and then 15-16, etc. These are known as your sample intervals.

3. At each one-meter interval, begin counting plants that touch, overlie, or underlie the transect line. For each plant encountered, record the type of plant (species or unique designation) and the length of the line that the plant intercepts. For plants that overhang the line, record the length of the imaginary vertical plane of the line that the plant would intercept.

a. Record this raw data for each interval in your field notebook. Also record any uncovered or bare lengths within the transect interval.

i. Frequency data will come from the number of times a particular species was found in all the different intervals that you surveyed, so be certain to take good notes organized by your interval.

that do not. The general questions are: Do invasive species alter plant diversity, abundance, and distribution? If so, do English Ivy and Pachysandra influence plant communities in the same way? Is there some characteristic of the respective plants that can be used to predict differences?

\section{Lab 2: Plant Survey}

The second lab begins with a short field quiz on the dominant plants at the field site. As I review the answers immediately, the quiz serves as a way to reinforce accurate plant identification. Any plants that cannot be identified during the survey are uniquely identified and collected. This collection

\section{Table \#1. Example of Raw Data.}

Interval $1 @ 2-3 \mathrm{~m}: \quad$ Species 1, $10 \mathrm{~cm}$ Bare ground, $20 \mathrm{~cm}$ Species $1,2 \mathrm{~cm}$ Species $2,20 \mathrm{~cm}$ Species $1,5 \mathrm{~cm}$ Species $3,100 \mathrm{~cm}$

Interval 2 @11-12 m: Species 3, $100 \mathrm{~cm}$ Species $4,2 \mathrm{~cm}$ Bare ground, $5 \mathrm{~cm}$ Species $5,85 \mathrm{~cm}$

Interval $3 @$ 15-16 m: Species 4, $1 \mathrm{~cm}$ Species $4,3 \mathrm{~cm}$ Species $3,100 \mathrm{~cm}$ Species $4,2 \mathrm{~cm}$ Species $5,90 \mathrm{~cm}$ allows for standardization of the unknowns among all student teams. Plant identification, however, need not be a major component of this project. If a study site with only a few species can be located, then the entire study can be completed with any arbitrary identifying labels. Alternatively, plant identification can become another component of this lab module. If another lab session is added, a collection of all plants at the study site can teach students about plant pressing and the significance of type collections and herbaria. In any case, the ecological concepts and data analysis do not require correct plant names. Furthermore, invasive species are not required either. Nearly any site will have a gradient or organizing feature of some sort that can be identified. The line-intercept method can then be used to collect data along gradients or identified sub-zones of the study site.

During the second three-hour session, student teams collect data from 25 meter transects; two transect lines in native, less disturbed regions and two from a region with a preponderance of either English Ivy or Pachysandra. Most teams have plenty of time to return to the classroom and enter the data into MS Excel spreadsheets. I accept emailed files for those teams that need a bit more time. I then compile all the data into one large data set to be used in the final lab session on data analysis.

\section{Lab 3: Analyzing Plant Community Structure with Descriptive Statistics}

As a pre-class assignment, students are asked to construct a graph that compares plant community structure in native habitats to those dominated by invasive species. It is purposefully an open-ended question designed to challenge students to summarize their data. Comparing different graphs that students submit serves as starting point for the instruction on analyzing the survey data. As a class we expand the Excel spreadsheet with all the compiled data to include calculations on relative frequency, relative abundance, and relative coverage (see Figure 2 for a flowchart on these calculations). Next, we calculate the Shannon's index (Figure 3A) and discuss the different attributes
Figure 2. Example calculations of relative frequency, relative abundance, and relative coverage.

First, organize all raw data by species as follows (from example data in Table 1):

\begin{tabular}{|c|c|c|c|c|}
\hline \multicolumn{5}{|c|}{ Summary of Raw Data } \\
\hline Species $_{i}$ & & $\begin{array}{c}f_{i}=\text { Number of inter- } \\
\text { vals in which species; } \\
\text { occurs }\end{array}$ & $\begin{array}{c}n_{i}=\text { Number of individu- } \\
\text { als encountered }\end{array}$ & 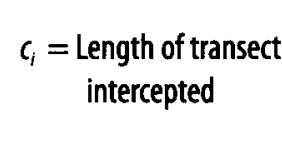 \\
\hline Species 1 & & 1 & 3 & 17 \\
\hline Species 2 & & 1 & 1 & 20 \\
\hline Species 3 & & 3 & 3 & 300 \\
\hline Species 4 & & 2 & 4 & 8 \\
\hline \multirow[t]{2}{*}{ Species 5} & & 2 & 2 & 175 \\
\hline & & $\mathrm{F}=$ Total & $\mathrm{N}=$ Total & $C=$ Total $\_520$ \\
\hline $\begin{array}{l}\text { Relative freq } \\
\text { Relative abu } \\
\text { Relative cove }\end{array}$ & e & $\begin{array}{l}=f_{i} / \mathrm{F} \Rightarrow \text { for Spe } \\
=n_{i} / N \Rightarrow \text { for Spe } \\
=c_{i} / C \Rightarrow \text { for Spe }\end{array}$ & $\begin{array}{l}\text { es } 1: 1 / 9=0.11 \\
\text { es } 3: 3 / 13=0.23 \\
\text { es } 5: 175 / 520=0.34\end{array}$ & \\
\hline
\end{tabular}


Figure 3. Formulas for two diversity indices: A. The

Shannon's Index. B. The Simpson's Reciprocal Index.

A.

$$
\begin{gathered}
H^{\prime}=-\sum_{(-\rightarrow-)} p_{1} \ln \left(p_{1}\right) \\
\text { Or } \\
H^{\prime}=-\left[p_{3} \ln \left(p_{1}\right)+p_{2} \ln \left(p_{2}\right)+p_{3} \ln \left(p_{3}\right)+\ldots+p_{s} \ln \left(p_{s}\right)\right]
\end{gathered}
$$

Where the ps are the proportion of all observations in the $i^{\text {th }}$ species category, and $S$ is the total number of species.

$$
\text { B. } \left.\quad D=1 / \Sigma_{(i-\Omega)}(n / N)\right)^{2}
$$

Where ns are the number of individuals observed in the ith species category, $N$ is the total number of all individuals of all species and $S$ is the total number of species.

The value $(n / N)$ is equivalent to $p_{i}$ from the formula in Part A. Therefore, the Simpson's Reciprocal index can be re-written as:

$$
D=1 / \Sigma_{(i-s)}\left(p_{i}\right)^{2}
$$

of this and other diversity indices. Shannon's index $\left(H^{\prime}\right)$ not only accounts for species richness or the number of different species, but also accounts for the evenness of each species. New species that are rare affect the index much less than species that are more common. For example, a habitat with five species found in equal proportions has a larger Shannon's value than a habitat of five species where only one species is dominant. If the exponent is taken of Shannon's index $\left(e^{H^{\prime}}\right)$, it is converted to a value called "equivalent common species" that falls between 1 and the total number of species. Thus, in the example above, the habitat with one dominant species has an "equivalent common species" value close to 1 and the habitat with five equally common species has an "equivalent common species" value of 5 even though each habitat has five total species. Simpson's Reciprocal Diversity Index has the same attributes as the Shannon's index, but has the benefit of not requiring the extra step necessary to find "equivalent common species." The value is always between 1 and the total number of species. However, the Simpson's Reciprocal Index cannot be used in statistical test comparing habitats, because it is not based on a statistical distribution. (See below for a discussion of the Kolmogorov-Smirnov test of significance). Figure 3B shows the formula for calculating the Simpson's Reciprocal Index and is preferred if the Kolmogorov-Smirnov test will be omitted. Calculating the Simpson's Reciprocal Diversity Index does not require knowledge of the exponential function and is thus more accessible to a larger diversity of learners.

Next, we construct a graph of relative frequency of species in each of the two habitats. We repeat the process for each parameter and discuss the merits of each graph. This exercise demonstrates for students how different methods of data presentations are better or worse at illustrating particular trends in data. In the data collected from the student projects, species diversity changes little or irregularly over the habitats, but the coverage of dominant species is dramatically changed by the presence of invasive species. In this particular study, a graph of relative coverage best captures the effects of invasive species on plant community structure.

\section{Extensions}

If time allows, I require the non-parametric KolmogorovSmirnov test to be conducted on habitat types. Boyce (2005), from the Teaching Issues and Experiments in Ecology (TIEE) Web site, details the methods and includes Excel spreadsheets with example data. Essentially it tests for differences in the trajectories of two bounded cumulative frequency distributions which, as it turns out, perfectly characterize the plant survey data from the line-intercept method comparing two habitat types. The abundance data is ranked and the cumulative abundances from each habitat type are subtracted from each other. The greatest of these differences is compared to a calculated critical value (Boyce, 2005) for a test of significance.

\section{Interpreting the Data: Correlation Versus Causation \& Community Ecology}

Building graphs and/or running statistical tests provide students with two important opportunities. First, students pick up on more subtle differences and, second, this leads to more refined questions regarding the trends in the data set. Before answering some of those questions, it is worthwhile to talk to students about the difference between correlation and causation. This particular field study is a description of two pre-defined habitats based on the presence or absence of a plant-invasive species. Therefore, any differences observed are only correlated with the pre-defined habitats. A good question for students to ponder is, "How would one design an experiment that would provide evidence for a causal link between their findings and the invasive species?" This helps students learn the difference and merits of descriptive versus experimental science. For example, descriptive studies are not able to distinguish between the questions of whether invasive species affect community structure or community structure allows for invasion. However, if one designed an experiment with controls to remove an invasive

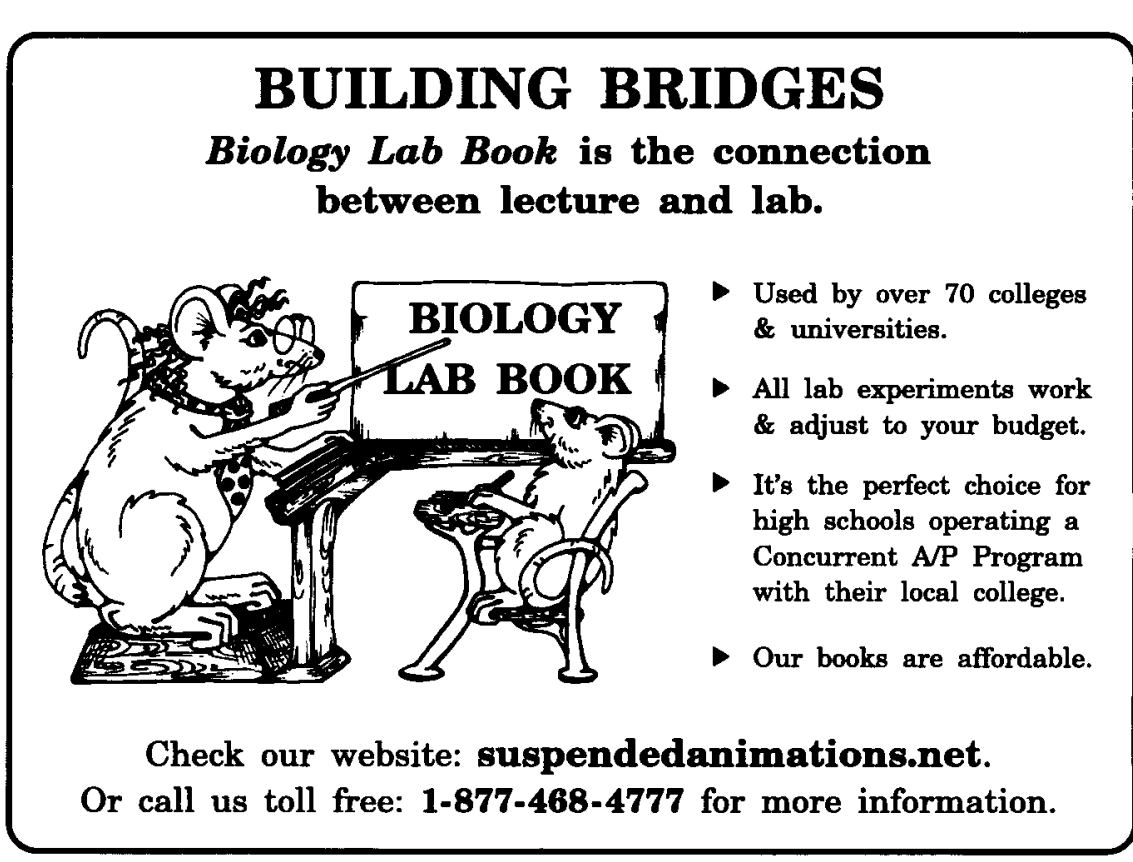


emphasis of the lab course in general on making and interpreting observations. The work and discussions in class give students a good start on generating graphs as well as an understanding of the relevant ecological concepts at play. It is their task to demonstrate an ability to synthesize the data, present the main trends with properly-labeled graphs, and link biological concepts into a well-reasoned interpretation. If learning to write scientific reports is a primary objective, a full report with Introduction, Methods, Results, and Discussion sections is well-suited for this activity.

MASTBR OF SCIENCB N GENERAL BIOLOGY

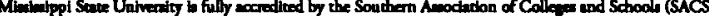

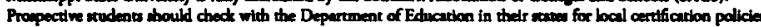

For more information, visit:

Www.distance.msstate.edu/tib

or contact:

jbailey@aoce.msstate.edu

662.325 .9684 this 33 -hour program is taught online*

Join students from around the world

to earn a Master of Science degree

through distance learning from

Mississippi State University! species and/or transplant some to an unaffected location, then any changes over time could be attributed to the experimental treatment. In other words, it could be said that the invasive species "cause" certain effects.

Regardless of whether the data are correlations or causal effects, any result is not complete without interpretation. If one assumes the causal effects, what is the biological mechanism producing this effect? And do all invasive species cause the same effect? If one believes it is the structure of the community that allows for invasion, what factors of structure influence this relationship? Does it depend on the habitat? Whether it is a forest or grassland? These questions are related to the biology of the invasive species and the ecology of a habitat. For example, English Ivy is a groundcover and climbing vine. In full sun it grows very dense, but in the shade will be disperse enough to allow other species to grow between its vines. As a result, it excludes some, but not all, low-lying plant species. In addition, it climbs large trees, blocks out their access to light, and weakens them until they fall or are blown down. Pachysandra, on the other hand, cannot climb, but clones itself vigorously into dense expansive mats that exclude nearly all other groundcover. The biology of plants can help explain the observations and leads to the development of a hypothesis regarding effects of invasive species.

Furthermore, an understanding of the ecological concepts of succession, competitive exclusion, and ecological functional groups can help students explain the observations they collected. A forest in a colonizing stage will more than likely be affected differently then one in a late climax stage. Competitive exclusion is the mechanism by which invasive species lower diversity in susceptible habitats. Habitats with few members of ecological functional groups may or may not be more susceptible to invasion. All these concepts add depth and scope to students' ability to make sense of their findings and are excellent topics for lectures and discussions connected to the activities outlined above.

\section{Assessment}

To assess student learning, I require a modified lab report consisting of Results and Discussion sections. This parallels the
The find coppone course it 8-10 den on boation. Misssistippl State IUNIVESTYY \%Arademic Outreach $\triangle$ Continuing Education

\section{Conclusion}

In this field study project, students have the chance to learn local plant species, investigate issues of invasive species, use the line-intercept method of plant sampling, gain experience in experimental design, practice summarizing data with descriptive statistics and, depending on their level, learn more elaborate statistical tests. Students are surprisingly hungry to learn to identify the dominant plant species around their campus environs. Most notably, several of my students used their picture phones to generate their own digital archive of the species they learned. If this lab helps students resolve the "green blur" into identifiable components, then it has served its purpose. Further, the issue of invasive species has many implications for other ecological sub-disciplines, such as population ecology, functional ecology, and evolutionary ecology. Hopefully this lab will serve as a broad and engaging introduction to further ecological investigations.

\section{References}

Boyce, R.L. (April 2005, posting date). Life Under Your Feet: Measuring Soil Invertebrate Diversity. Teaching Issues and Experiments in Ecology, Vol. 3: Experiment \#1. Available online at: http://tiee. ecoed.net/vol/v3/experiments/soil/abstract.html.

Campbell, N.A. \& Reece, J.B. (2005). Biology, 7th Ed. San Francisco, CA: Benjamin/Cummings Publishing Company, Inc.

Cummings, J. \& Smith, D. (2000). The line-intercept method: A tool for introductory plant ecology laboratories. In S.J. Karcher (Ed.), Tested Studies for Laboratory Teaching, Vol. 22 (pp. 234246). Proceedings of the 22nd Workshop/Conference of the Association for Biology Laboratory Education (ABLE).

Pimentel, D., Zuniga, R. \& Morrison, D. (2005). Update on the environmental and economic costs associated with alien-invasive species in the United States. Ecological Economics, 52, 273-288.

United States Department of Agriculture. (Last modified: 2008). What is an invasive species? Available online at: http://www. invasivespeciesinfo.gov/whatis.shtml.

Vitousek, P.M. (1990). Biological invasions and ecosystem processes: Towards an integration of population biology and ecosystem studies. Oikos, 57(1), 7-13.

Wandersee, J.H. \& Schussler, E.E. (1999). Preventing plant blindness. The American Biology Teacher, 61(2), 84-86.

Zavaleta, E.S. \& Hulvey, K.B. (2006). Realistic variation in species composition affects grassland production, resource use and invasion resistance. Plant Ecology, 188, 39-51. 